\title{
DERMATIOMIOSITE COM DOENÇA INTERSTICIAL PULMONAR - UMA ASSOCIAÇÃO COM ANTI-MDA-5
}

\author{
Leonor Ramos', Miguel Gouveia', José Carlos Cardoso², Margarida Robalo Cordeiro² \\ 'Interna(o) Dermatologia e Venereologia/Resident, Dermatology and Venereology \\ ${ }^{2}$ Assistente Hospitalar de Dermatologia e Venereologia/Consultant, Dermatology and Venereology \\ Serviço de Dermatologia e Venereologia do Centro Hospitalar e Universitário de Coimbra, Coimbra, Portugal
}

RESUMO - A dermatomiosite (DM) é uma doença auto-imune com atingimento cutâneo, muscular e pulmonar. O MDA-5 (melanoma differentiation-associated protein 5) foi recentemente descrito como alvo de uma resposta serológica específica da DM que está associada a maior risco de doença pulmonar. Doente do sexo feminino, 54 anos, com fraqueza muscular proximal, mialgias, incapacidade funcional marcada e sinais cutâneos de dermatomiosite. Analiticamente apresentava elevação da aldolase e CK, e electromiografia e biópsia muscular compatíveis com dermatomiosite. A TAC pulmonar revelou padrão em vidro despolido. O estudo de auto-imunidade mostrou anti-MDA-5 positivo forte. Não foi detectada neoplasia. $O$ tratamento com prednisolona $20 \mathrm{mg}$, hidroxicloroquina $400 \mathrm{mg}$ e metotrexato $20 \mathrm{mg} / \mathrm{semana}$ levou a melhoria apenas discreta do quadro, pelo que se introduziu imunoglobulina endovenosa (lgIV), com melhor resposta. Descreve-se o caso de uma doente com DM e doença intersticial pulmonar grave, com anti-MDA-5 positivo, chamando a atenção para esta associação até há pouco desconhecida.

PALAVRAS-CHAVE - Autoanticorpos; Dermatomiosite; Doenças pulmonares intersticiais.

\section{DERMATOMYOSITIS WITH INTERSTITIAL LUNG DISEASE - AN ASSOCIATION WITH ANTI-MDA-5}

ABSTRACT - Dermatomyositis is a systemic autoimmune disease with cutaneous, muscular and pulmonary involvement. MDA-5 has recently been described as a specific dermatomyositis target antigen associated with a higher risk for interstitial lung disease. A 54-year-old female patient presented with proximal muscular weakness, myalgia and cutaneous signs of dermatomyositis. She presented with high aldolase and CK levels, and the muscular biopsy and electromyography were consistent with dermatomyositis. Pulmonary CT scan showed ground glass appearance. Autoimmunity revealed strong anti-MDA-5 positivity. No neoplasm was detected. She began treatment with prednisolone $20 \mathrm{mg}$, hydroxicloroquine $400 \mathrm{mg}$ and methotrexate $20 \mathrm{mg} /$ week with very little improvement. She then began IVIG, with better clinical response. The authors report a case of dermatomyositis with interstitial lung disease associated with anti-MDA-5, an association unknown until recently.

KEY-WORDS - Autoantibodies; Dermatomyositis; Lung diseases, interstitial.

Trabalho apresentado como Poster/Presented as a Poster, Reunião de Primavera da SPDV/SPDV Spring Meeting, 2014

Conflitos de interesse: Os autores declaram não possuir conflitos de interesse.

No conflicts of interest.

Suporte financeiro: $O$ presente trabalho não foi suportado por nenhum subsídio ou bolsa.

No sponsorship or scholarship granted.

Direito à privacidade e consentimento escrito / Privacy policy and informed consent: Os autores declaram que pediram consentimento ao doente para usar as imagens no artigo. The authors declare that the patient gave written informed consent for the use of its photos in this article.

Recebido/Received - Dezembro/December 2014; Aceite/Accepted - Setembro/January 2015 


\section{Caso Clínico}

\section{Correspondência: \\ Dr. @ Leonor Ramos}

Serviço de Dermatologia e Venereologia

Centro Hospitalar e Universitário de Coimbra

Praceta Mota Pinto - 3000 Coimbra, Portugal

E-mail: leonoricr@gmail.com

\section{INTRODUÇÃO}

A dermatomiosite (DM) é uma doença auto-imune sistémica com atingimento cutâneo, muscular e pulmonar.

Caracteriza-se como uma doença bimodal (formas juvenil e adulta), sendo mais frequente no sexo feminino. ' Anticorpos anti-nucleares séricos circulantes são detectados em praticamente $95 \%$ dos indivíduos com DM, sendo os anticorpos específicos para a DM (anti-Jo-1 e anti-Mi-2) positivos em apenas uma pequena percentagem de doentes. ${ }^{1}$

Recentemente, o melanoma differentiation-associated protein 5 (MDA-5) foi descrito como alvo de uma resposta serológica específica da DM que é positiva em apenas $19-35 \%$ dos doentes, e que está associada a maior risco de doença pulmonar intersticial e a uma vasculopatia cutânea mais grave. ${ }^{2,3}$

\section{CASO CLÍNICO}

Uma doente do sexo feminino de 54 anos anos de idade é referenciada à Consulta Externa com história de fraqueza muscular proximal, mialgias, incapacidade funcional marcada e perda de peso $(8 \mathrm{~kg})$ desde há um ano. Referia ainda astenia e dispneia para pequenos esforços. Concomitantemente surgiram eritema heliotropo, pápulas de Gottron (algumas das quais ulceradas), eritema triangular do decote e região dorsal, sinal do coldre, eflúvio difuso, bem como distrofia das cutículas e telangiectasias peri-ungueais (Fig. 1). Não havia história sugestiva de fenómeno de Raynaud, nem lesões palmares.

Analiticamente apresentava elevação da aldolase $(10.3 \mathrm{U} / \mathrm{L} ; \mathrm{N}<7.6), \mathrm{LDH}(359 \mathrm{U} / \mathrm{L} ; \mathrm{N}<247)$ e da CK $(280 U / L ; N<145)$.

Foram realizadas electromiografia (que revelou lesão da fibra muscular do deltóide direito) e a biópsia muscular do músculo deltóide esquerdo (com evidente atrofia perifascicular e infiltrado mononuclear perivascular), ambas compatíveis com DM.

A biopsia cutânea realizada numa pápula de
Gottron revelou hiperqueratose ortoqueratósica, com vacuolização focal da camada basal e de camadas superiores da epiderme associadas a infiltrado inflamatório mínimo (dermatite de interface paucicelular). A imunofluorescência directa foi negativa.

Pelas queixas respiratórias havia já sido realizada TAC pulmonar de alta resolução que mostrou padrão em vidro despolido com sinais de fibrose periférica em ambos os campos pulmonares associados a áreas de enfisema nos segmentos posteriores de ambos os lobos inferiores. As provas funcionais respiratórias (PFR) revelaram alterações compatíveis com fenómenos restritivos, com diminuição da capacidade de difusão de CO (DLCO) e da pressão inspiratória máxima. O ECG não revelou alterações da condução cardíaca.

O estudo da auto-imunidade evidenciou ANAs positivos (++ padrão mosqueado), sendo os anticorpos clássicos associados a miosites (anti-Jol, anti-Mi2 e anti-SRP) negativos. Foi pedido estudo complementar de anticorpos associados a miosite, dada a grande suspeita clínica de DM, que revelou positividade anti-MDA-5 (positivo forte).

O estudo complementar realizado não detectou neoplasias ocultas.

Foi feito o diagnóstico de DM e instituído tratamento

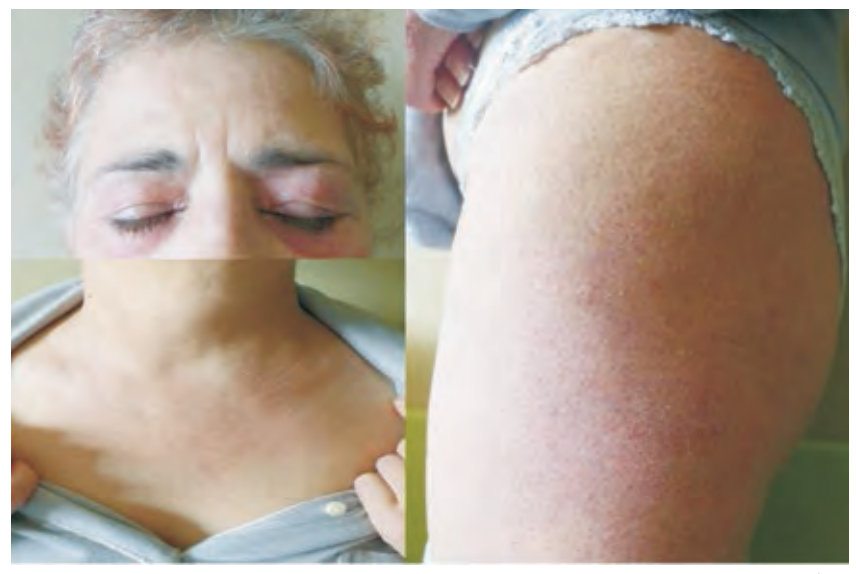

Fig. 1 - Eritema heliotropo, eritema do decote e sinal do coldre. 


\section{Caso Clínico}

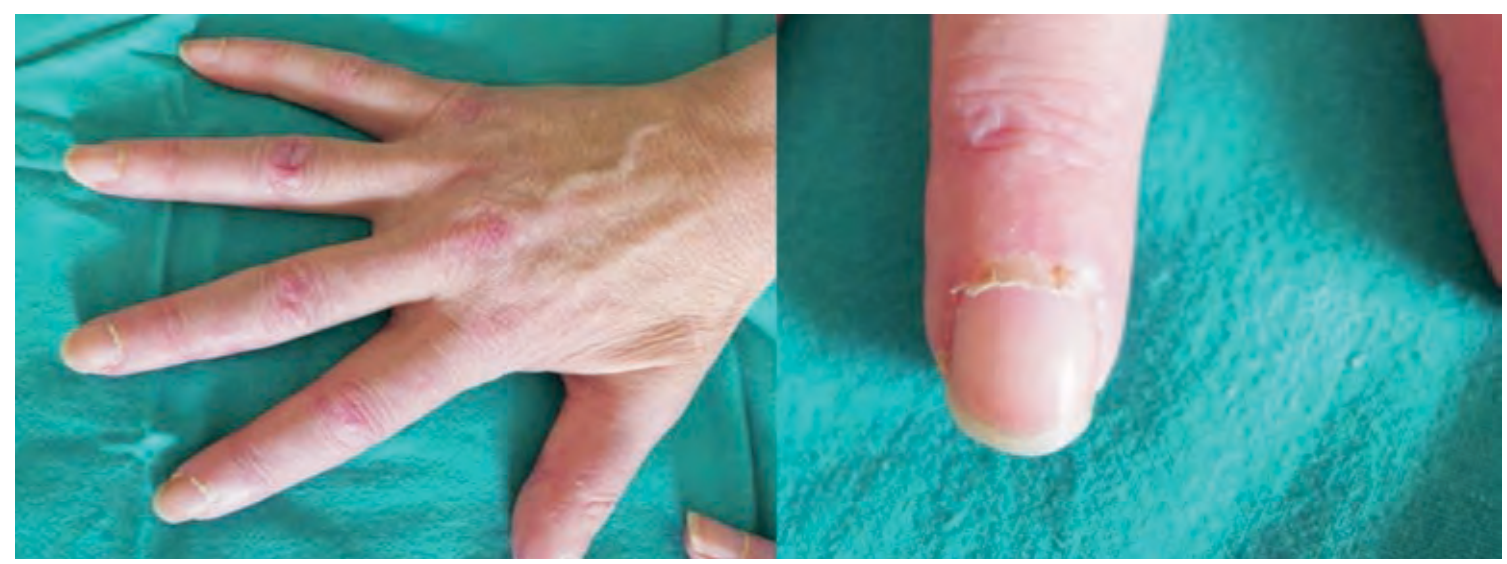

Fig 2 - Pápulas de Gottron, algumas com pequenas ulcerações. Telangiectasias peri-ungueais associadas a distrofia cuticular.

com prednisolona (inicialmente $60 \mathrm{mg}$ com desmame progressivo - em cerca de 10 meses - para $20 \mathrm{mg}$ ), hidroxicloroquina $400 \mathrm{mg}$ e metotrexato $12,5 \mathrm{mg} / \mathrm{se}-$ mana (com aumento até $20 \mathrm{mg} / \mathrm{semana}$ ) que levou apenas a melhoria discreta do quadro clínico, persistindo as lesões cutâneas e as queixas musculares e respiratórias. Por esse motivo iniciou-se tratamento adicional com IgIV $(400 \mathrm{mg} / \mathrm{kg} /$ dia durante 5 dias com frequência mensal) durante um período de 6 meses. A doente referiu melhoria da sintomatologia, com diminuição das queixas álgicas e aumento da força muscular, bem como diminuição dos sinais cutâneos de DM, ao final de 2 ciclos de tratamento.

\section{DISCUSSÃO}

A DM é uma doença auto-imune que se manifesta por uma miopatia inflamatória proximal dos músculos extensores e lesões cutâneas. A característica cutânea mais importante da DM é a poiquilodermia que apresenta tonalidade tipicamente violácea. Ocorrem também eritema heliotropo, lesões nas superfícies extensoras, pápulas de Gottron, distrofia cuticular, telangiectasias peri-ungueais e descamação difusa do couro cabeludo com queixas de prurido. Os doentes com DM apresentam tipicamente queixas de fraqueza simétrica dos músculos proximais (essencialmente dos músculos extensores), com posterior generalização. Pode haver atingimento pulmonar em $15-30 \%$ dos doentes, com fibrose intersticial difusa. ${ }^{1}$

Tendo em consideração que cerca de $25 \%$ dos doentes adultos com DM podem ter uma neoplasia oculta subjacente, deve ser efectuado estudo adequado para exclusão de doença oncológica, com uma frequência de 6 meses nos primeiros 2 anos de doença.

O MDA-5 foi identificado como um auto-antigénio alvo em doentes com DM. É uma helicase específica de RNA que actua no reconhecimento de vírus de RNA, estando envolvida na resposta imune inata, incluindo na produção de interferão (IFN) do tipo 1..$^{3-5}$ Os estudos iniciais consideraram que os anticorpos

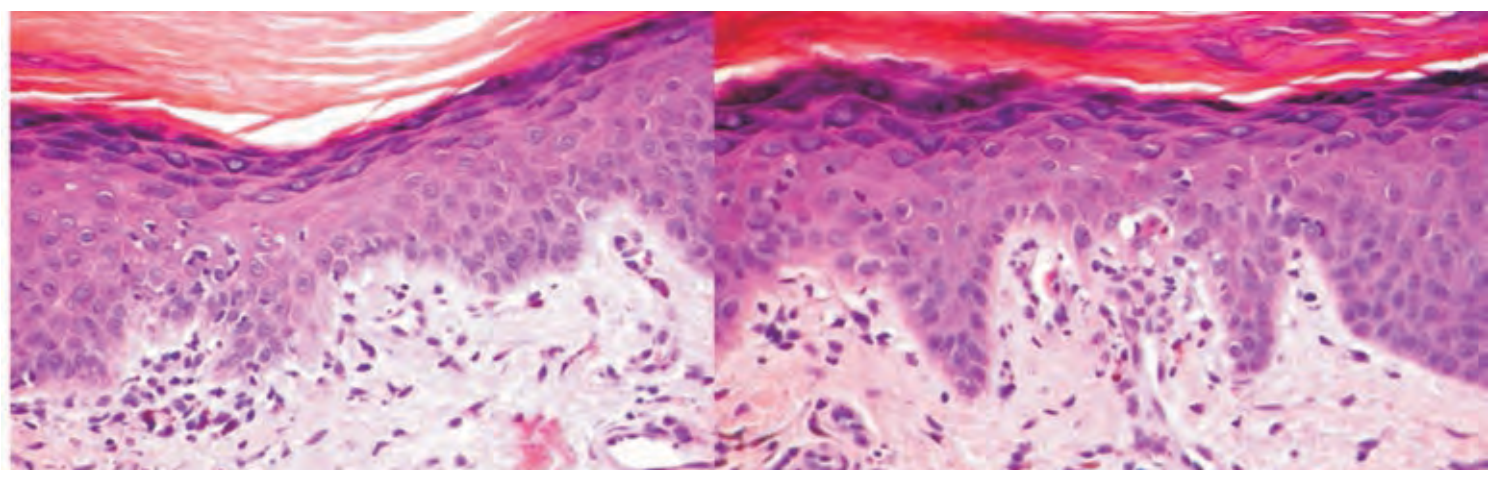

Fig 3 - Dermatite paucicelular com vacuolização focal da camada basal e raros queratinócitos apoptóticos (H\&E, 200x). 
anti-MDA-5 estariam associados a dermatomiosite com atingimento muscular mais discreto ou mesmo a DM amiopática. ${ }^{2-4}$ No entanto estudos mais recentes referem que estes anticorpos também ocorrem em doentes com miopatia, ${ }^{5}$ tal como ocorreu no nosso caso.

Do ponto de vista cutâneo os doentes com anti-MDA-5 estão mais susceptíveis a ulcerações (localizadas nas pregas ungueais laterais, pápulas de Gottron e cotovelos) e/ou pápulas palmares dolorosas. Podem também apresentar dor oral, edema das mãos, artrite inflamatória simétrica e perda capilar difusa, ${ }^{2,5}$ havendo também dados que sustentam maior frequência de paniculite nos doentes com anti-MDA- $5 .^{3}$

Embora todos os doentes com DM devam ser avaliados do ponto de vista pulmonar com realização de PFR e/ou TAC pulmonar de alta resolução, parece haver uma relação positiva entre a presença de anti-MDA-5 e doença pulmonar intersticial rapidamente progressiva. ${ }^{2-4}$

Os dados disponíveis até à data sugerem que a presença deste anticorpo estará menos associada a neoplasias do que outros anticorpos. ${ }^{2-4}$

O tratamento da DM difere se há atingimento sistémico ou se o atingimento é puramente cutâneo. Se houver atingimento muscular devem ser instituídos corticóides sistémicos, em desmame lento (cerca de 6-8 meses). Em casos resistentes ou avançados, ponderar-se-á a introdução de metotrexato, IgIV, clorambucil, ciclofosfamida, ciclosporina, micofenolato de mofetil ou rituximab. ${ }^{1,5}$

O tratamento do componente cutâneo da DM é até à data insuficiente e independente da resposta muscular. Baseia-se essencialmente na utilização de fotoprotectores e dermocorticóides, podendo associar-se fármacos sistémicos de que se destacam os antimaláricos, metotrexato ou micofenolato de mofetil.

Por norma, os doentes com anti-MDA-5 necessitam de doses maiores de corticóides sistémicos e de imunossupressores, em grande parte devido a doença intersticial pulmonar concomitante. ${ }^{4}$

Os autores descrevem o caso de uma doente com DM e doença intersticial pulmonar grave, com anti-MDA-5 positivo, chamando a atenção para esta associação até há pouco tempo desconhecida. Enfatiza-se também a importância da identificação de autoantigénios que se correlacionam com determinados fenótipos clínicos e que poderão ter impacto não só na escolha do tratamento, mas também no prognóstico.

\section{REFERÊNCIAS}

1. Jorizzo JL, Carroll CL, Sangueza OP. Dermatomyositis. In: Dermatology Bolognia JL, Jorizzo JL, Rapini RP, editors. 2 ${ }^{\text {nd }}$ Edition.Philadelphia: Mosby Elsevier; 2008. p.575-83.

2. Fiorentino D, Chung L, Zwerner J, Rosen A, Casciola-Rosen $\mathrm{L}$. The mucocutaneous and systemic phenotype of dermatomyositis patients with antibodies to MDA5 (CADM-140): a retrospective study. J Am Acad Dermatol. 2011; 65(1):25-34.

3. Labrador-Horrillo $M$, Martinez MA, SelvaO'Callaghan A, Trallero-Araguas E, Balada E, Vilardell-Tarres $M$, et al. Anti-MDA5 antibodies in a large mediterranean population of adults with dermatomyositis. J Immunol Res. 2014 (in press).

4. Hoshino K, Muro Y, Sugiura K, Tomita Y, Nakashima R, Mimori T. Anti-MDA5 and anti-TIF1- $\gamma$ antibodies have clinical significance for patients with dermatomyositis. Rheumatology. 2010; 49(9): 1726-33.

5. Hall JC, Casciola-Rosen L, Samedy LA, Werner J, Owoyemi K, Danoff SK, .et al. Anti-MDA-5 associated dermatomyositis: expanding the clinical spectrum. Arthritis Care Res. 2013; 65(8):1307-15. 